\title{
THE CALCULATION OF COOLING CURVE OF THE COMBUSTION BOILER REFRACTORIES LINING WITH USE OF AN EXPERIMENTAL DEVICE
}

\author{
R. Kukla, T. Vítěz, P. Trávníček, P. Sedlák
}

Received: February 6, 2012

\begin{abstract}
KUKLA, R, VÍTĚZ, T., TRÁVNÍČEK, P., SEDLÁK, P.: Calculation of cooling curve of the combustion boiler refractories lining with use of an experimental device. Acta univ. agric. et silvic. Mendel. Brun., 2012, LX, No. 3 , pp. 111-116

The aim of the work was modeling of cooling process dynamics of a combustion boiler and designing of the method, which is suitable for calculation of cooling time in a large scale of temperature. Methods were verified with the use of referential combustion boiler with heat output of $130 \mathrm{~kW}$. This boiler burned mixture of waste sawdust and shavings originating in the course of production of wooden furniture. For these purposes specialized experimental device has been used. Cooling curves were measured in interval from $380^{\circ} \mathrm{C}$ to $50^{\circ} \mathrm{C}$ and were described by using of polynomial function. The cooling time was calculated by using of polynomial function in full temperature scale for cooling of combustion boiler refractories lining, from $700^{\circ} \mathrm{C}$ to $50^{\circ} \mathrm{C}$.
\end{abstract}

cooling curve, combustion boiler, refractories lining, heat transfer coefficient

Measurment and evaluating of cooling curves is an integral part of the field of metalography. This issue is described in scientific works (Chen et. al., 2006; Li et al., 2008). In practise there is necessary to know the cooling dynamics of other materials that is not associated with a significant change in the crystalline as in the case of metallic materials. It includes metallic materials for example. Typical cases are heat devices such as combustion boilers for solid fuels. In this case the biggest amount of heat energy is accumulated in a refractory lining, which consists from a heat ressistant material such as fire clay. According to information given by producer of this material the temperature resistance of fire clay is about $1400{ }^{\circ} \mathrm{C}$. Measurment of a cooling dynamics is very important for maintenance of heat devices and for planing of temporary shutdown of heat devices. If the course of cooling dynamics is knowed, the temporary shutdown can be planned precisely, which means considerable financial savings. Accurate cooling dynamics measurment of large heat devices is technically and financially demanding. Endeavour of authors were to design a method, which is financially accetable and measured values relevant for practice. For this purpose experimental device, which proved success in experimental determination of temperatures of the inner wall of the combustion chamber of the boiler for the purpose of verification of a CFD model have been used. This experimental device has been designed at the Department of Agricultural, Food and Evironmental Engineering at Mendel University in Brno (Trávníček et al., 2011). For the purpose of testing of new method, the materials, which are commonly used as refractory lining in the combustion chamber of reference boiler with heat output of $130 \mathrm{~kW}$, have been used. The bases of refractory lining have been two layers of fire clay and one layer of porous insulating material with the trade name - Peril.

\section{MATERIAL AND METHODS}

The basis for the experimental device was a layer of lining material (fire clay) and insulation layer consisting of porous material, Peril. Both these materials are used in the reference device. The first layer from the fire clay measures 
$130 \mathrm{~mm}$ and second layer from Peril measures $65 \mathrm{~mm}$. These layers of materials have been subsequently insulated by using of mineral wool $\left(\rho=150 \mathrm{~kg} \cdot \mathrm{m}^{-3} ; \lambda=0,049 \mathrm{~W} \cdot \mathrm{m}^{-1} \cdot \mathrm{K}^{-1}\right)$ and placed on a resistance heater with heat output of $1200 \mathrm{~W}$ (Fig. 1). Temperatures of the inner and outer surfaces of the layer have been measured in the time interval of 1 second by two T-type thermoelectric couples with measurement range from $-200{ }^{\circ} \mathrm{C}$ to $400{ }^{\circ} \mathrm{C}$. The typical deviation was $\pm 1{ }^{\circ} \mathrm{C}$ while the maximum deviation was $\pm 1.5^{\circ} \mathrm{C}$. Measured values were compiled by measuring transducer ADAM (Fig. 2) and subsequently evaluated. Further measured values were saved into the file by user real time application, which was created in ControlWeb softwate environment (Fig. 3). The first layer of refractory lining was heated to the temperature 380 ${ }^{\circ} \mathrm{C}$. When required temperature was reached, the electric heater was turned off. Temperatures of inner and outer side of refractories lining were measured for a period of twelve hours. Measured values were evaluated by using of Microsoft Excel and Matlab software. Afterwards values were plotted into graphs which were interspersed by tendentious curves. Then the function of tendentious curve and the determination coefficient were calculated. Grubbs' test for outliers was executed, as well. Measurments of values were executed in atmospheric temperature $23{ }^{\circ} \mathrm{C}$ and barometric pressure $99600 \mathrm{kPa}$. Experiment was repeated threetimes. The final values were averaged.

\section{RESULTS AND DISCUSSION}

First of all basic physical properites of materials used for refractory ligning of boiler have been defined. The important physical property is heat transmission coefficient. The dependence of the heat transmission coefficient on the temperature was converted into a chart on the basis of the data sheets pertaining to individual materials used for isolation of the boiler. The dependence of the heat transmission coefficient on the temperature for the fire clay is shown in Fig. 4. The dependence of heat transmission coefficient on the temperature for the insulation material (Peril) is shown in Fig. 5. Both the figures document the fact, that the function characterizing the respective dependence is exponential. The determination coefficient applicable to the function characterizing the

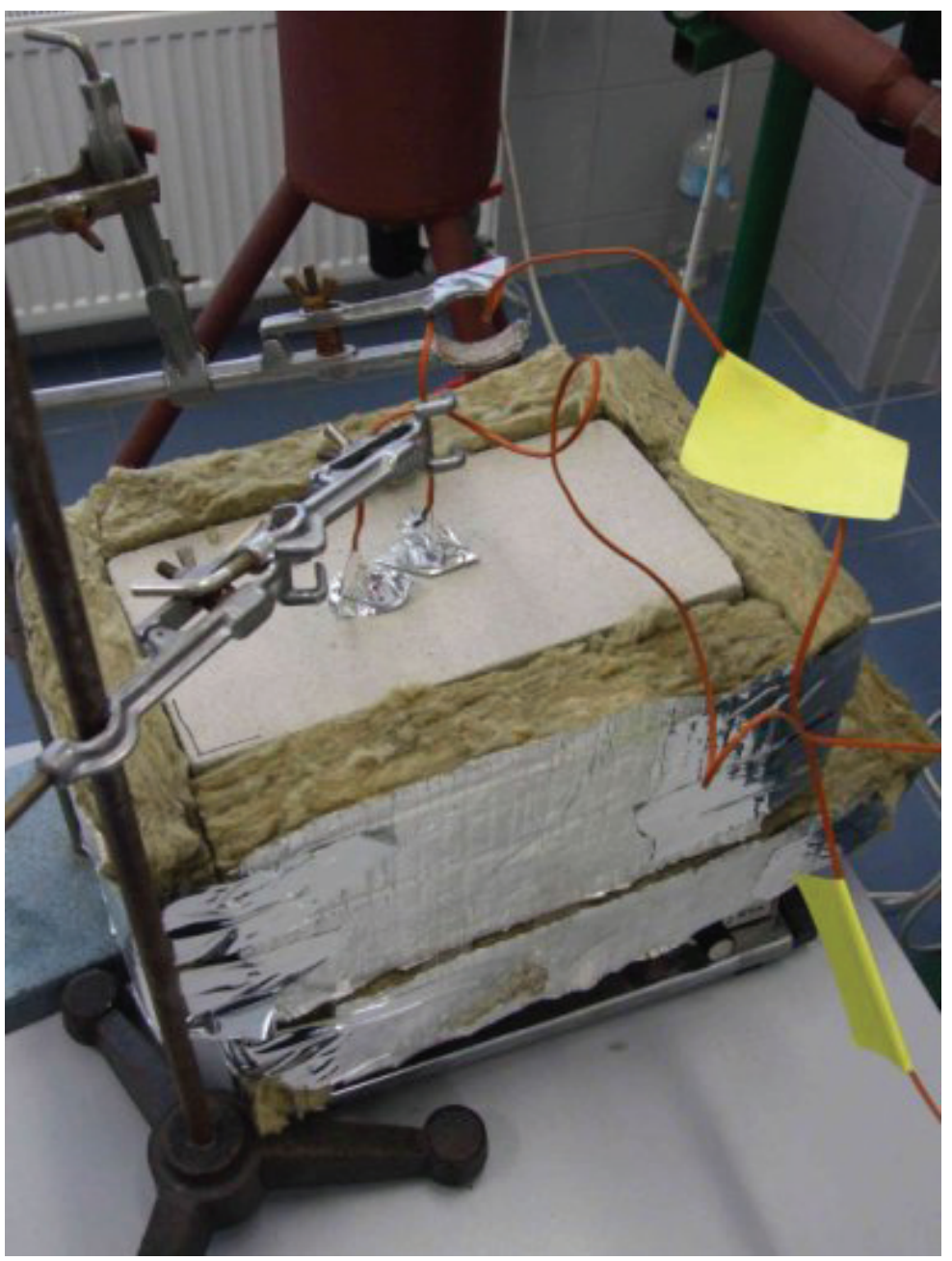

1: Experimental device 


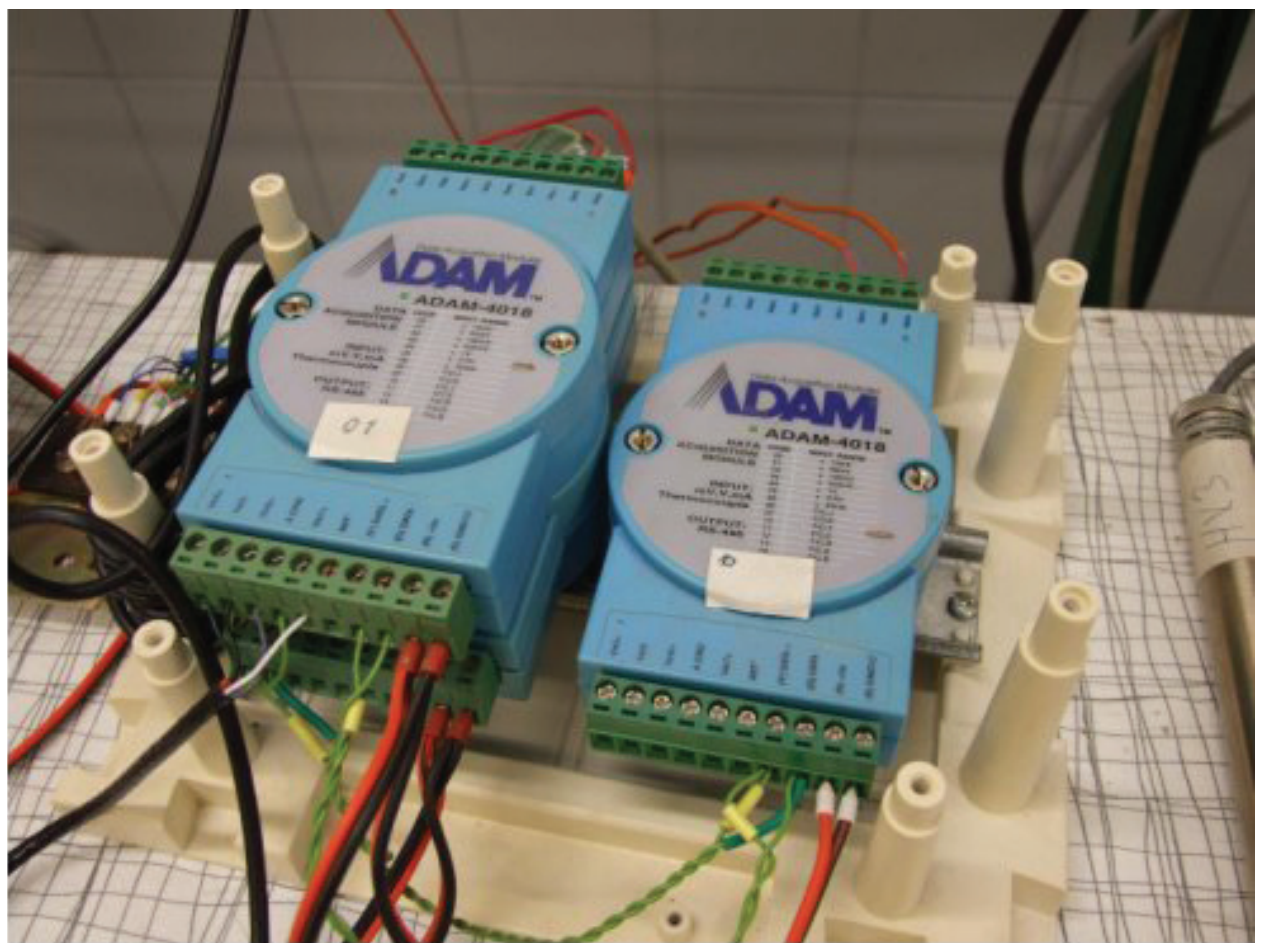

2: External modules for data collection

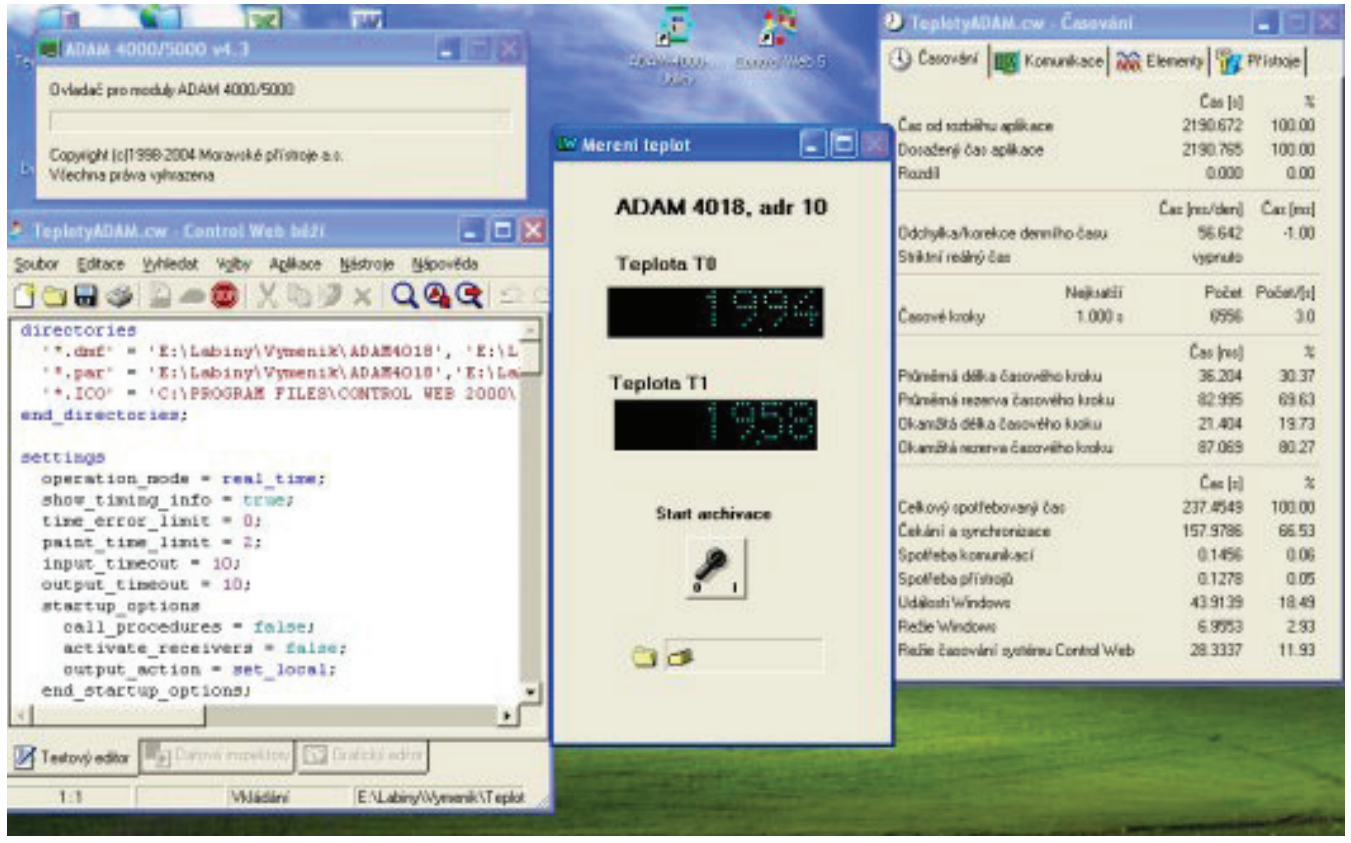

3: Graphical user interface for experimental measurment and data collection

dependence of heat transmission coefficient on the temperature for the fire clay was $\mathrm{R}^{2}=0.99$ and for the Peril was $\mathrm{R}^{2}=0.97$.

The experimental device performed measurement in the temperature range from $25{ }^{\circ} \mathrm{C}$ to $400{ }^{\circ} \mathrm{C}$. In total, more than 64000 values were recorded and evaluated. The cooling dynamics of inner wall is shown in Fig. 6. The outer surface cooling dynamics of the boiler is shown in Fig. 7. The following stage of measurement was supposed to comprise heating of a layer of material using a gas burner in order to determine cooling dynamics from temperature $700{ }^{\circ} \mathrm{C}$. This temperature is commonly achieved in cobustion boiler for combusting of biomass (Trávníček et al., 2011; Lavric et al., 2004; Novozhilov et al., 1996). However, due to safety reasons the experiment was terminated (the propane-butane cylinder was overheated). Aborting of experiment 


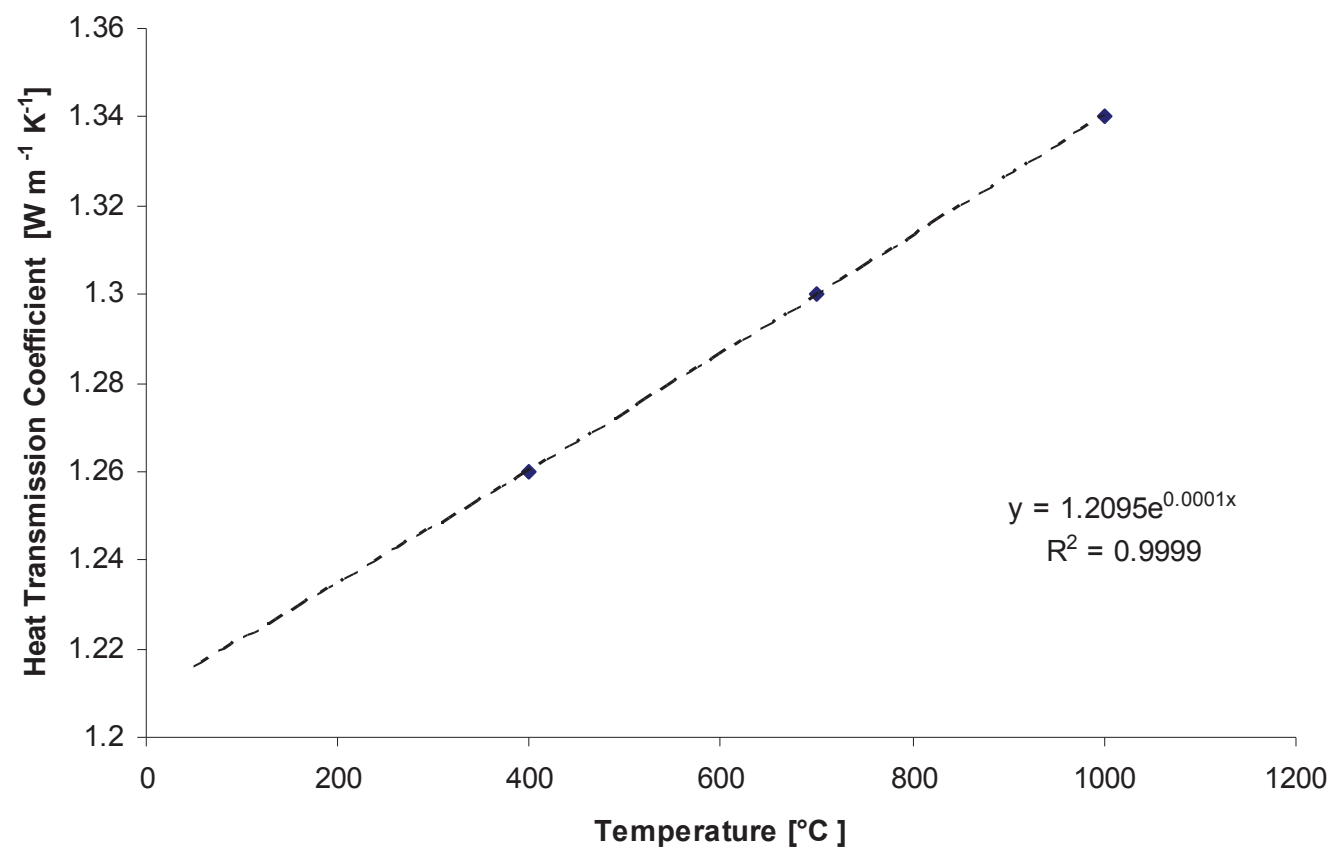

4: Dependence of the heat transmission coefficient of the fire clay on the temperature

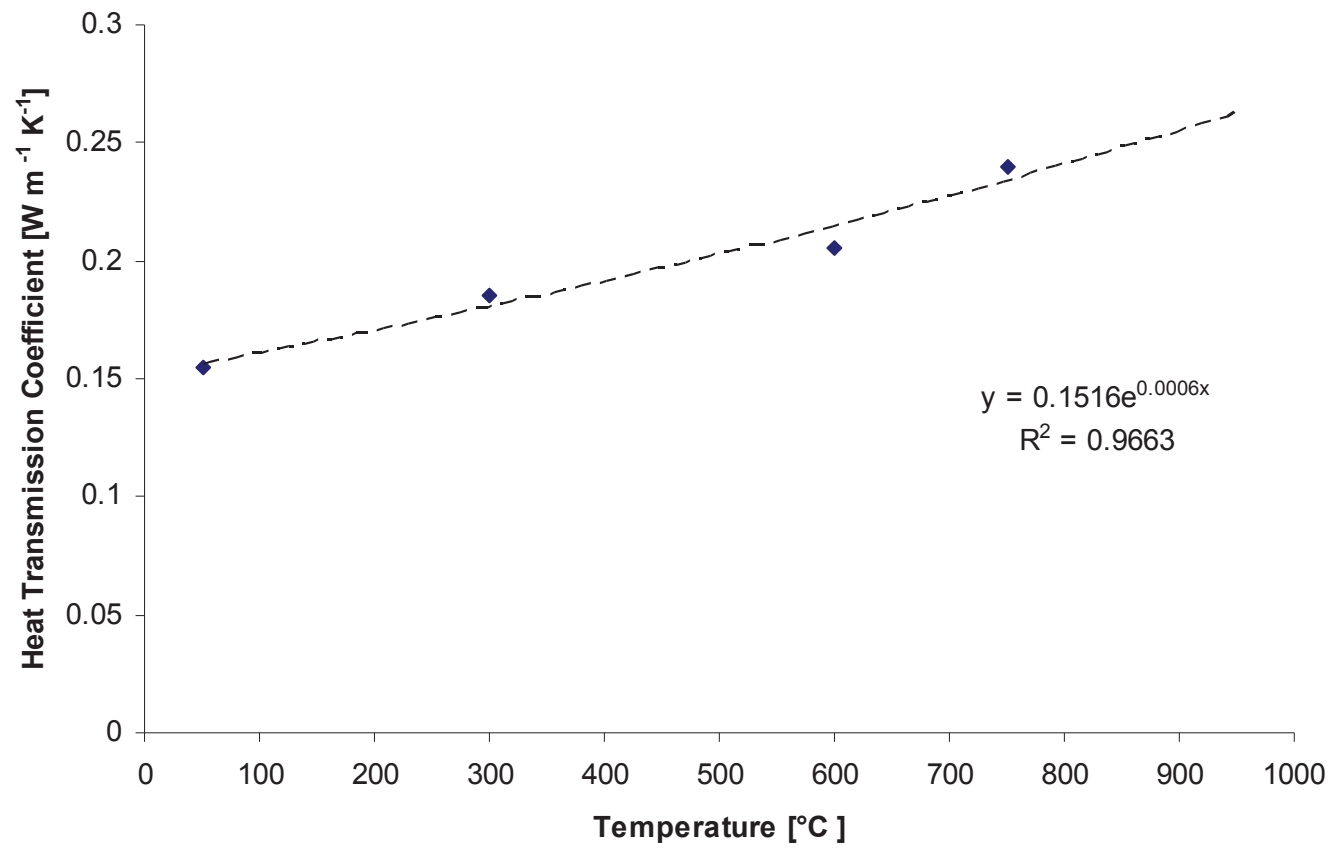

5: Dependence of the heat transmission coefficient of the peril on the temperature

was executed in temperature of $400{ }^{\circ} \mathrm{C}$. However it was proved that progress of this curve is acorrding to scientific work (Trávníček et al., 2011).

The calculation showed that curve trend, which defined the dynamics of inner refractory lining cooling was given by polynomial function:

$$
\begin{gathered}
y=7 \times 10^{-16} \times x^{4}-6 \times 10^{-11} \cdot x^{3}+2 \times 10^{-6} \times x^{2}- \\
-0.0369 x+381.34
\end{gathered}
$$

The trend of this curve is shown in Fig. 6. Coefficient of determination of this curve was
$\mathrm{R}^{2}=0.9998$. It was necessary to express roots of polynomial functions for $y=700$. In this way we have obtained the time, which is necessary for refractory lining cooling from temperature $700{ }^{\circ} \mathrm{C}$ to temperature $50{ }^{\circ} \mathrm{C}$. After calculation of roots is obvious that absolute value of the real root is $\underline{x}=6166$. This value idicated, how long does it take to cool refractory lining from temperature $700{ }^{\circ} \mathrm{C}$ to temperature $380{ }^{\circ} \mathrm{C}$. From experimental measurement it is obvious, that combustion chamber have been cooled down from temperature 


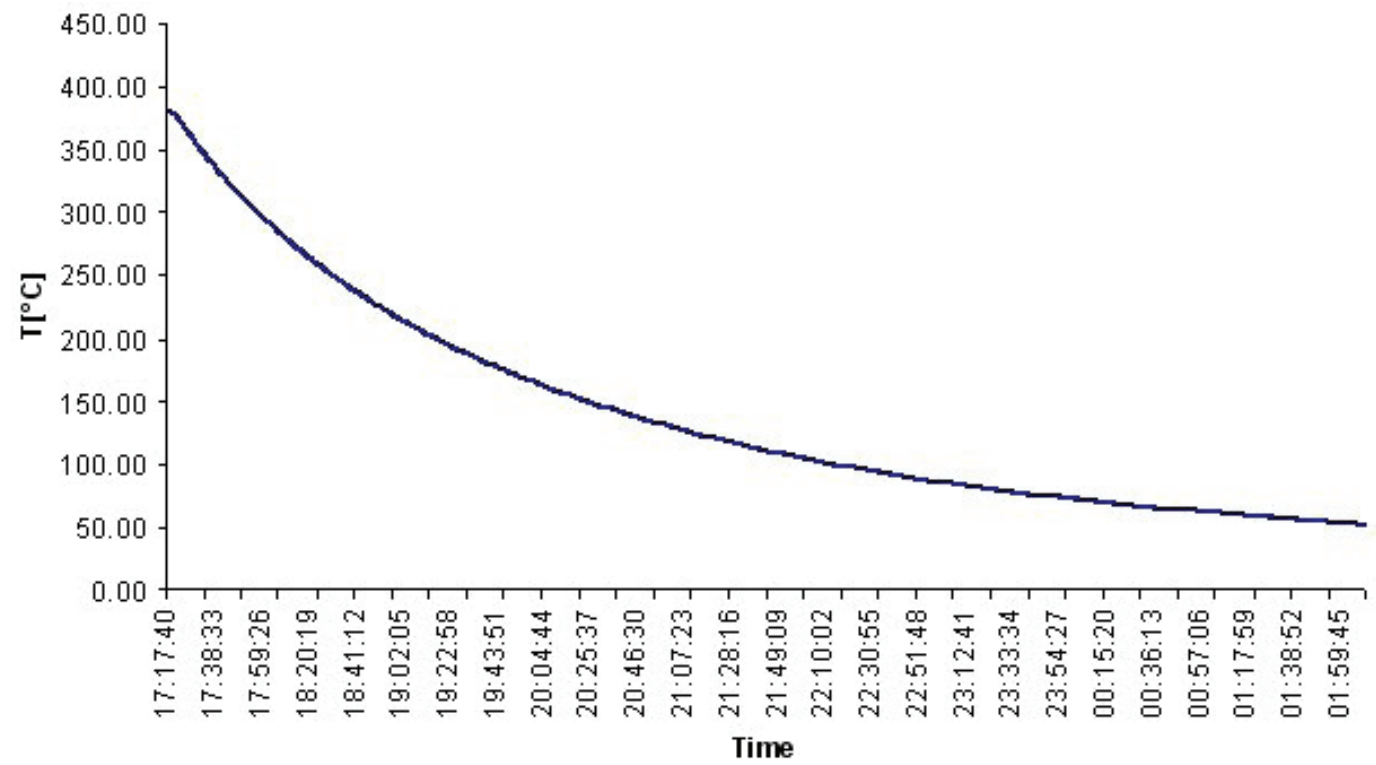

6: Dynamics of refractory lining cooling

$380{ }^{\circ} \mathrm{C}$ to temperature $50{ }^{\circ} \mathrm{C}$ for 33898 seconds. If both values are summed, total time for refractory lining cooling from temperature $700{ }^{\circ} \mathrm{C}$ to temperature $50{ }^{\circ} \mathrm{C}$ is 40064 seconds, which means approximately 11 hours and 8 minutes.

Calculation of outside surface cooling dynamics of combustion boiler was the same like in the previous case. From calculations the curve of oustside surface cooling of combustion boiler has been derived. The curve is shown in Fig. 7. Coefficient of determination was $\mathrm{R}^{2}=0.9962$. A function of curve is given by polynomial functions of third order:

$y=9 \times 10^{-13} \times x^{3}-4 \times 10^{-8} \times x^{2}-8 \times 10^{-5} \times x+44.878(2)$

Polynomial roots were expressed from this equation and than real value $\underline{x}_{i}$ have been calculated.

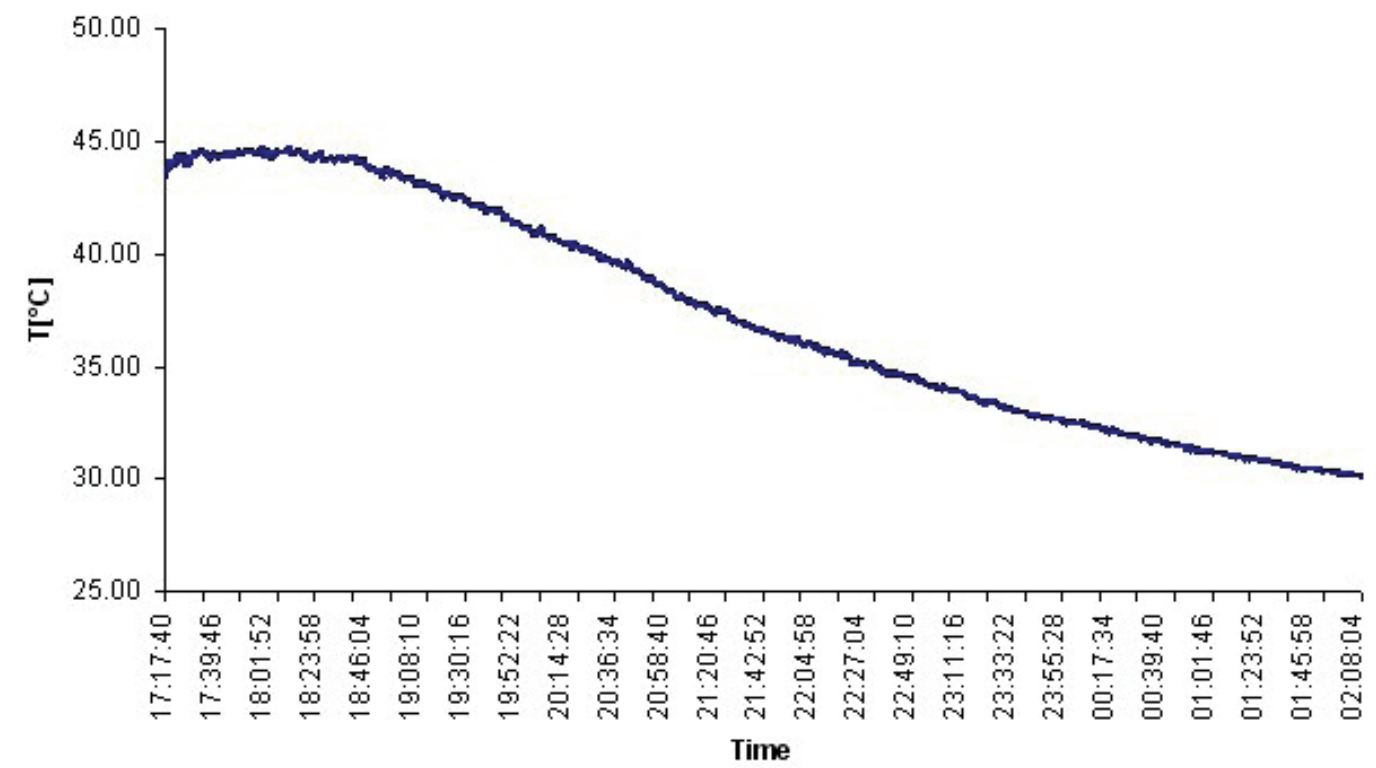

7: Dynamics of combustion boiler surface cooling

\section{SUMMARY}

The aim of the work was to evaluate dynamics of combustion device cooling. Further goal was to designe method for determination of the cooling time of boiler refractory lining in any temperature range. For this purpose an experimental device has been used. By using of this experimental device, 
temperature was collected every second for approximately 9 hours. Temperatures were measured on outside surface of refractory lining and inside surface of refractory lining. The database with 64000 values was created in this way. The range of temperatures was from $380{ }^{\circ} \mathrm{C}$ to $50{ }^{\circ} \mathrm{C}$. Dependence of decreasing temperature was described by using of polynomial functions of fourth order. In the similar way dependence of surface temperature of refractory linings on the time was described in the temperature range from $380^{\circ} \mathrm{C}$ to $50^{\circ} \mathrm{C}$. In the first case coefficient of determination was $\mathrm{R}^{2}=0.9998$ and in the second case coefficient of determination was $\mathrm{R}^{2}=0.9998$. Cooling time of inside surface of refractory linings was approximately 9 hours and 20 minutes. Based on a polynomial function the cooling time was calculated, and it was approximately 11 hours and 8 minutes in the temperature range from $700^{\circ} \mathrm{C}$ to $50^{\circ} \mathrm{C}$.

\section{Acknowledgment}

This study was supported by the Research plan No. MSM6215648905 "Biological and technological aspects of sustainability of controlled ecosystems and their adaptability to climate change", which is financed by the Ministry of Education, Youth and Sports of the Czech Republic.

\section{REFERENCES}

CHEN, X., GENG, H., LI, Y., 2006: Study on the eutectic modification level of Al-7Si Alloy by computer aided recognition of thermal analysis cooling curves. Materials Science and Engineering A 419, 283-289.

LAVRIC, E. D., KONNOV, A. A., DE RUYCK, J., 2004. Dioxin levels in wood combustion-a review. Biomass and Bioenergy, 26: 115-145.

LI,Z., LI, Y., ZHOU, R., 2008: Melt Quality Evaluation of Ductile Iron by Pattern Recognition of Thermal
Analysis Cooling Curves. Tsinghua Science and Technology. 13 (2): 142-146. ISSN 1007-0214.

NOVOZHILOV, V., MOGHTADERI, B., FLETCHER, D., F., KENT, J. H., 1996: Computational Fluid Dynamics Modelling of Wood Combustion. Fire Safety Journal, 27: 69-84.

TRÁVNÍČEK, P., KUKLA, R., VÍTĚZ, T., MAREČEK, J., 201l: Experimental determination of temperatures of the inner wall of a boiler combustion chamber for the purpose of verification of a CFD model. 